\title{
Characterization of Extracted Dissolved Gas from Water
}

\author{
Jeong-A Hong, Jong-Soo Lee ${ }^{2}$, and Yong-Du Jun ${ }^{3 *}$ \\ Kongju National University, Korea \\ ${ }^{1}$ hongjeonga@naver.com, ${ }^{2}$ jonglee@kongju.ac.kr, ${ }^{3 *} y j u n @ k o n g j u . a c . k r$
}

\begin{abstract}
The present study deals with the characterization of extracted dissolved gas from water in terms of its oxygen concentration and the total amount of gas extracted. This topic has long been the interest from scuba divers because the extracted dissolved gas is believed to have higher oxygen concentration due to the higher solubility of oxygen in water than that of nitrogen. However, the study results on the actual extraction of dissolved gas from water are rare. In the present study, a degassing process based on micro-vapor-bubble diffusion is proposed to demonstrate the availability of dissolved gas mixture of higher oxygen content than the standard atmosphere. A genuine experimental apparatus featured by micro-vapor-bubble generation along with a gas collector hood is prepared for the present study. The captured gas under a lower pressure then is reverted to atmospheric condition for the volume and the oxygen concentration measurements. Two test case results, one for depressurization only and the other for depressurization with micro-vapor-bubble diffusion, are presented to demonstrate the effectiveness of the latter which showed superior extraction performance. The proposed process based on micro-vapor-bubble diffusion seems promising and is expected to find practical applications not only in life science, food and beverage industry, but also in transport safety fields to mention a few.
\end{abstract}

Keywords: Degassing, Solubility, Vapor-bubble diffusion

\section{Introduction}

The dissolved gas in liquids and its treatment has long been an interesting issue from many and diversified applications such as so called "artificial gills" [1], deaeration processes in food and beverage industry, and in energy industry [2][3][4]. The efforts to develop artificial gills include studies to develop underwater breathing systems that can directly extract and separate dissolved oxygen (DO) from water, most approaches of which rely on polymeric membrane technologies or hollow fibers to obtain DO from pressurized water as noted by Lee et al., [1]. One of the key drawbacks of this pressure driven membrane technology is that the process requires significant amount of external energy mainly for pressurization. Deaeration refers to the removal of dissolved gases, such as oxygen, from liquids. Pressure deaerators, known to be the most efficient, and are used in all the power plants, relies its operation on the diffusion of gas between the oxygen-free steam and the sprayed droplets, in which steam not only contributes to the diffusion of gas between the two phases (liquid phase droplets to gas-phase steam) but also heats the fine water droplets near to saturation temperature. Spray deaerators which are typically composed of highly pressurized feed water inlet, a deaerator vessel with necessary arrangements, steam supply, feed pump and vacuum pump, which makes the system a bulky

Article history:

Received (January 20, 2021), Review Result (February 25, 2021), Accepted (April 7, 2021) 
and highly energy consuming ones. Jun et al., [5] recently proposed a process for extracting dissolved gas from liquids which is based on the diffusion between the vapor-bubbles (gas phase) and the liquid water (liquid phase) which is the opposite situation from the conventional deaerators, in which diffusion happens between the steam vapor and the sprayed droplets. The vapor-bubbles are generated through a generic micro-bubble generator under the already lowered environmental pressure, through which degassing or deaeration can be achieved in a simpler and energy-saving way.

In the present study, we attempted to demonstrate that it is possible to extract oxygenenriched air from water by using a vapor-bubble diffusion process. Theoretical background of the present methodology is briefly introduced with related physics and the experimental approach and the results are presented which include the measurement of the oxygen concentration of the extracted dissolved gas from water and the total amount of gas extracted.

\section{Related physics}

\subsection{Solubility and the expected dissolved gas composition}

Henry's law states that the solubility is proportional to the partial pressure of species and the proportionality constant is termed as Henry's constant. For a water solution,

$$
G_{a q}=k P_{g}
$$

where $G_{a q}$ is the solubility (mol/L·atm), k is Henry's constant, and $P_{g}$ is the partial pressure of a gas (atm). [Tables 1] shows the values of Henry's constants of oxygen, nitrogen and carbon-dioxide.

Table 1. Henry's constants for various gases in water at $25^{\circ} \mathrm{C}$

\begin{tabular}{|c|c|c|}
\hline Henry's constant in water & Unit & Value \\
\hline $\mathrm{k}_{\mathrm{O}_{2}}$ & \multirow{4}{*}{$\mathrm{mol} /(\mathrm{L} \cdot \mathrm{atm})$} & $1.28 \times 10-3$ \\
\cline { 1 - 1 }$k_{\mathrm{N}_{2}}$ & & $6.48 \times 10-4$ \\
$k_{\mathrm{CO}_{2}}$ & & $3.38 \times 10-2$ \\
\hline
\end{tabular}

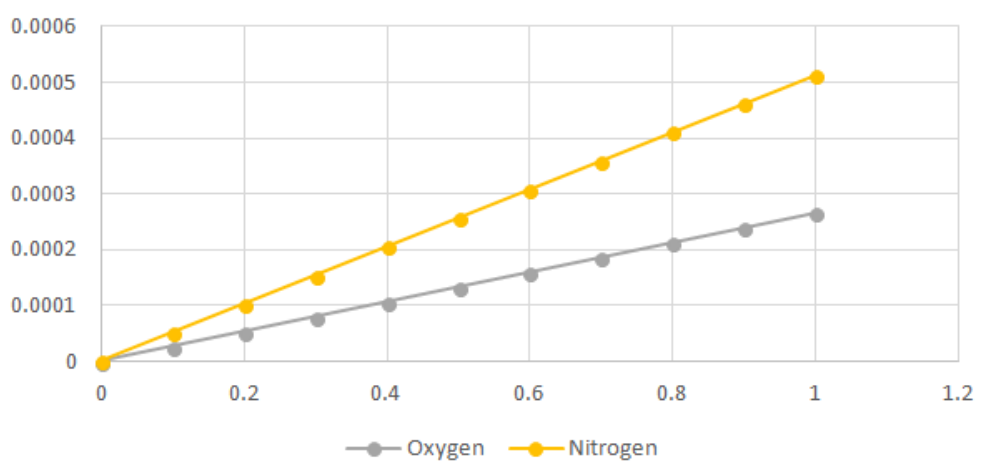

Figure 1. Dissolved gas amount $(\mathrm{mol} / \mathrm{L})$ in water for different atmospheric pressures at $25^{\circ} \mathrm{C}$ 
Assuming the idealized atmospheric air is composed of oxygen and nitrogen with volume fractions of $20.9 \%$ and $79.1 \%$, respectively, with Henry's constants shown in [Table 1], the limiting number of dissolved gases (oxygen and nitrogen) can be calculated and is shown in [Figure 1].

For 1 ton of water with equilibrium condition with atmosphere, for example, conceivable total amount of extracted gas would be $17.2 \mathrm{~L}$ that is composed of $5.9 \mathrm{~L}$ of oxygen and $11.3 \mathrm{~L}$ of nitrogen, resulting in the expected oxygen concentration of $\frac{2.34}{2.34+4.46} \times 100=34.4 \%$.

\subsection{Vapor-bubble generation}

Vapor bubbles are virtually cavitation bubbles that may appear when the local pressure diminishes down below the vapor pressure of the liquid. For the vapor pressure of water is a function of temperature as shown in [Figure 2], one may have two options to get vapor bubbles, that is, either raising temperature to saturation condition (boiling) or lowering down pressure to the same (vapor bubble generation). In the present study, the latter approach is pursued.

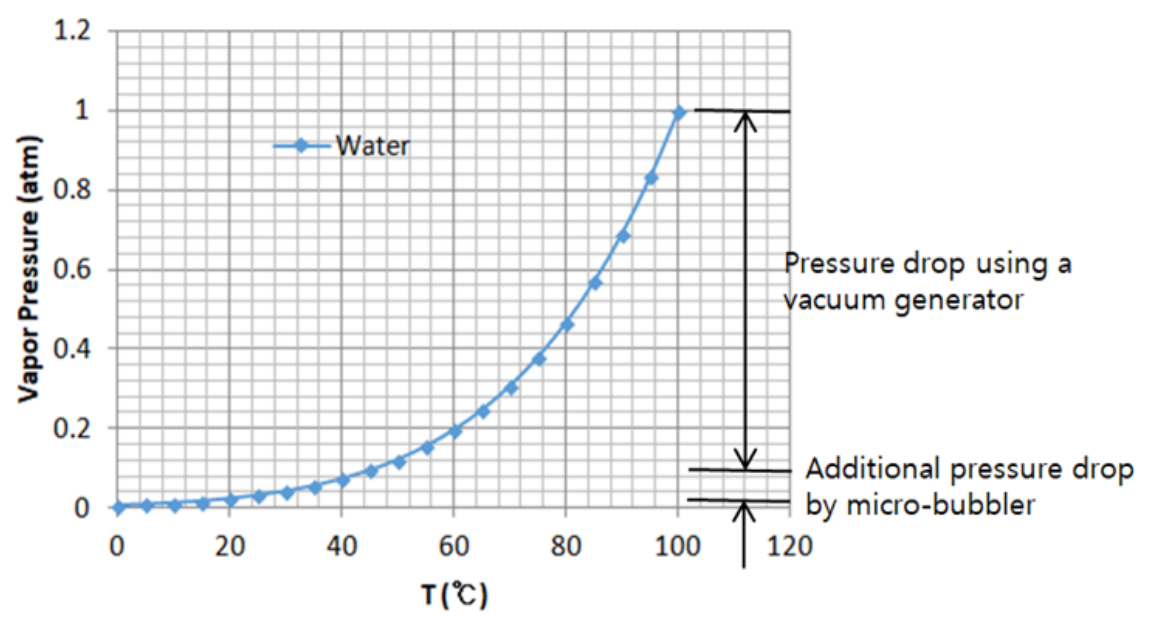

Figure 2. Vapor pressure of water with respect to temperature (data from ref. [6])

\section{Methods}

In order to effectively extract dissolved gas, first we generate micro-sized vapor bubbles through micro-bubbler under a lowered pressure condition as indicated in Figure 2. For the vapor bubbles so generated should have very low oxygen concentration inside due to the volume expansion from liquid water to vapor bubbles while the water body contains certain level of oxygen, the diffusion process of dissolved oxygen in water body into vapor bubbles may proceed during the time the bubbles move around and finally arrive at water surface where the bubbles eventually burst out. The burst-out gas is a mixture of water vapor and extracted dissolved gas and is captured inside the collector hood maintaining a saturated (100\% R.H.) condition. Once the collector is filled up by the extracted gas, degassing terminates and the measurements of total volume and oxygen concentration proceed. The tank pressure is reverted to atmospheric conditions before the measurements in order to avoid additional pressure correction. This process is repeated until the captured volume increase becomes no longer appreciable. 


\subsection{Test apparatus and testing procedure}

[Figure 3] illustrates the test apparatus used in the present study. It is composed of a sealed water tank with a depressurization system, a micro-bubble generator, a gas collector hood, and measurement system. The water tank is $0.65 \mathrm{~m}(\mathrm{~L}) \times 0.65 \mathrm{~m}(\mathrm{~W}) \times 1.0 \mathrm{~m}(\mathrm{H})$ in size and is equipped with two large viewing windows. The tank which is designed for low pressure operation with perfect seal so it can maintain vacuum state long enough as needed [7] is modified to capture the extracted dissolved gas by adopting a gas collector hood system for the present study.

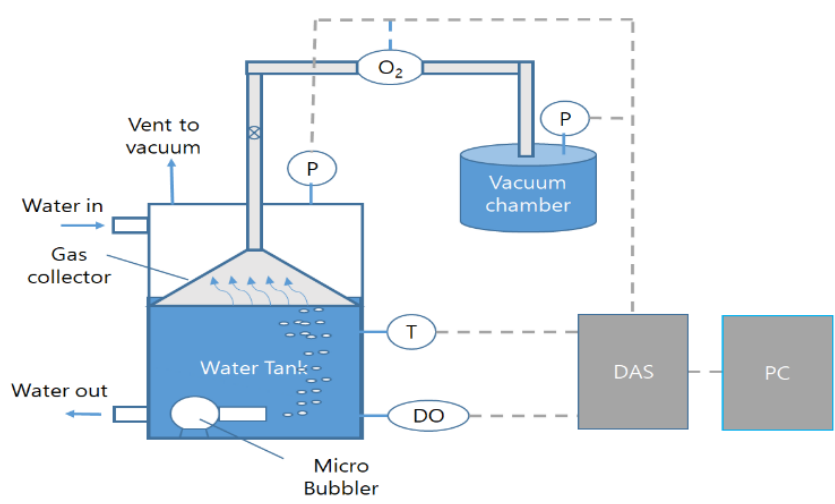

Figure 3. A diagram of the test apparatus for capturing and measuring extracted gas from water

Depressurization is achieved by using a vacuum generator which is connected to a compressor for air supply. A micro-bubble generator with a counter-rotating blades is installed at the outlet of a DC driven small water pump.
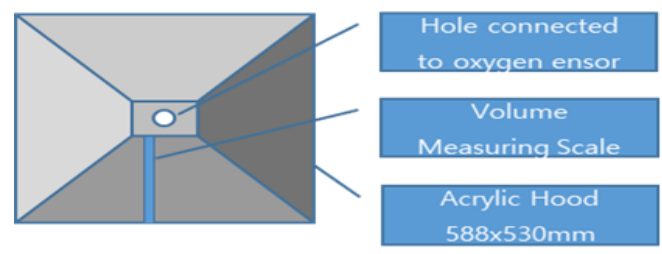

(a)

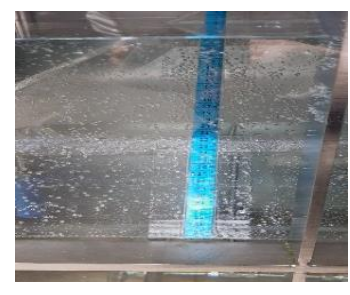

(b)

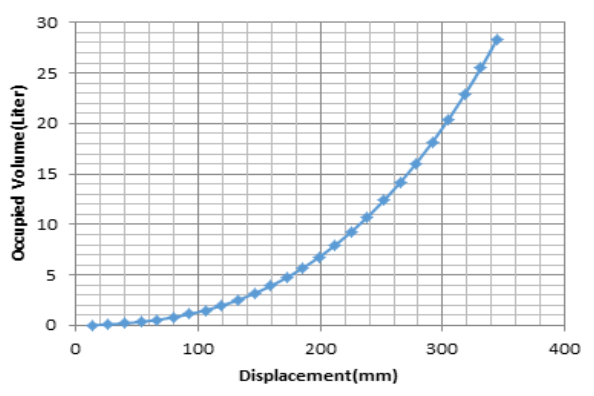

(c)

Figure 4. (a) Gas collector overall configuration, (b) measurement scale at work, (c) relation between the measured displacement and the volume 
A gas collector hood with a measurement scale as shown in Figure 4(a) and 4(b) collects the burst-out gas. The captured gas volume is obtained by reading the water level, with the aid from a calibration curve for the gas volume vs. the scale level as shown in [Figure 4(c)]. In the present study the maximum level the hood may hold is set up to be $23 \mathrm{~cm}$ of displacement on the scale. The testing procedure for degassing and measurement is illustrated in [Figure 5].

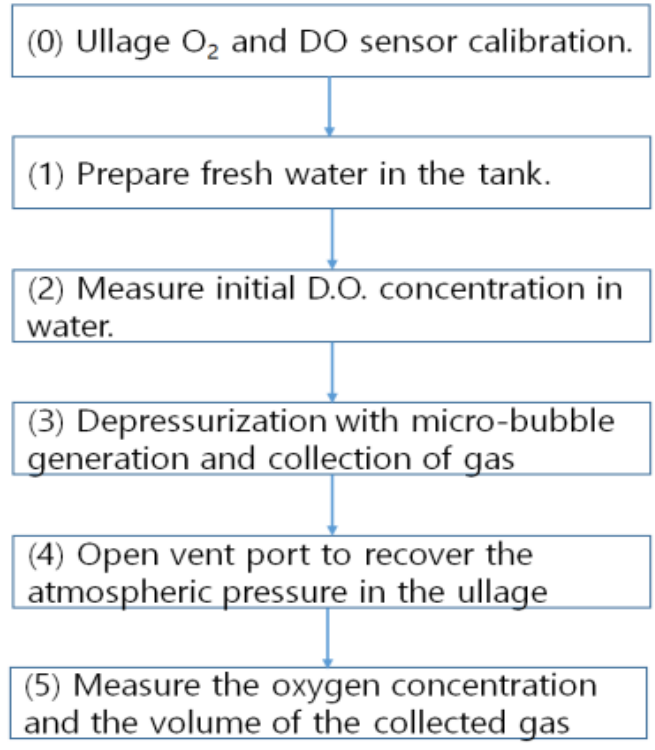

Figure 5. Testing procedure for degassing and measurements

\subsection{Test conditions and methods}

The D.O. concentration of the fresh tap water of 296 liter (70\% loading), initially $17.2 \%$, reaches $18.6 \%$ after 30 minutes of aeration at $30 \mathrm{slpm}$. In order to demonstrate the difference between the depressurization only and the vapor bubble diffusion the tests are conducted in two steps, i.e., (1) case I: depressurization only ( $0.1 \mathrm{~atm}$ or $10 \mathrm{kPa})$ and case II: vapor bubble diffusion (depressurization combined with vapor bubble generation).

\section{Results and discussion}

\subsection{Case I results: Depressurization down to 0.1 atm $(10 \mathrm{kPa})$}

Table 2. Degassed gas measurement results with depressurization at $0.1 \mathrm{~atm}(10 \mathrm{kPa})$

\begin{tabular}{|c|c|c|c|c|}
\hline Test Date & \multicolumn{4}{|c|}{ Test Condition Description } \\
\hline $11 / 27 / 20$ & $\begin{array}{c}\text { Before } \\
\text { depressurization }\end{array}$ & $\begin{array}{c}\text { After 25 min. of } \\
\text { depressurization }\end{array}$ & $\begin{array}{c}\text { After 57 min. of } \\
\text { depressurization }\end{array}$ & $\begin{array}{c}\text { Pressure } \\
\text { recovered to } 1 \text { atm }\end{array}$ \\
\hline $\begin{array}{c}\text { Tank pressure } \\
\text { (outside the hood) }\end{array}$ & $100 \mathrm{kPa}$ & $10 \mathrm{kPa}$ & $100 \mathrm{kPa}$ \\
\hline $\begin{array}{c}\text { Water surface level } \\
(\mathrm{cm})\end{array}$ & 0 & 10.5 & 11.8 & 3.7 \\
\hline Gas volume (liter) & $0.009 *$ & $1.492+0.009 *$ & $1.940+0.009 *$ & $0.199+0.009 *$ \\
\hline
\end{tabular}




\begin{tabular}{|c|c|c|c|c|}
\hline $\begin{array}{c}\text { Oxygen } \\
\text { concentration }(\%)\end{array}$ & 20.9 & Not measured & Mot measured & Not measured \\
\hline $\begin{array}{c}\text { D.O. concentration } \\
(\%)\end{array}$ & 18.6 & N.A. & N.A. & Not measured \\
\hline
\end{tabular}

* the line volume of $9 \mathrm{~cm}^{3}$

"[Table 2]. Degassed Gas Measurement Results with Depressurization at 0.1 atm (10kPa)" shows the test results of depressurization-only-case. In this case, the gas bubbles continue to be generated in the water, but the rate of volume increase was observed very slow. The tank pressure is recovered to the atmospheric pressure resulting in the shrink of the gas volume as shown in the table. The gas volume at atmospheric pressure, is measured to be 0.15 liters (water level scale reading of $3.7 \mathrm{~cm}$ ) which is about $2.6 \%$ of total dissolved gas of 5.86 liters in 296 liter of water at reference temperature of $25^{\circ} \mathrm{C}$.

\subsection{Case II results: Vapor bubble generation and depressurization down to $0.1 \mathrm{~atm}$ (10kPa)}

Table 3. Degassed gas measurement results with vapor bubble diffusion with depressurization at 0.1 $\operatorname{atm}(10 \mathrm{kPa})$

\begin{tabular}{|c|c|c|c|c|c|}
\hline Test Date & \multicolumn{5}{|c|}{ Test Condition Description } \\
\hline $\begin{array}{c}11 / 27 / 20,11 / 28 / 20, \\
12 / 4 / 20,12 / 5 / 20\end{array}$ & Round 1 & Round 2 & Round 3 & Round 4 & Round 5 \\
\hline $\begin{array}{c}\text { Tank pressure } \\
\text { (outside the hood) }\end{array}$ & $100 \mathrm{kPa}$ & $100 \mathrm{kPa}$ & $100 \mathrm{kPa}$ & $100 \mathrm{kPa}$ & $100 \mathrm{kPa}$ \\
\hline $\begin{array}{c}\text { Water surface } \\
\text { level(cm) }\end{array}$ & 9.4 & 9.2 & 10.2 & 9.2 & 9.1 \\
\hline $\begin{array}{c}\text { Gas volume (liter) } \\
\text { concentration }(\%)\end{array}$ & $1.17+0.009^{*}$ & $1.11+0.009^{*}$ & $1.40+0.009^{*}$ & $1.11+0.009^{*}$ & $1.09+0.009 *$ \\
\hline $\begin{array}{c}\text { D.O. concentration } \\
(\%)\end{array}$ & 15.2 & 31.9 & 30.5 & 29.3 & 27.7 \\
\hline
\end{tabular}

* the line volume of $9 \mathrm{~cm}^{3}$

After the depressurization only tests, a combined degassing process with vapor bubble generation is further conducted. According to the test results, it was possible to capture the total volume of 5.88 liter at $100 \mathrm{kPa}$ which is very close to the expected value of 5.09 liters for the test condition. For more strict comparison, it was necessary to consider the effect of temperature. For the actual testing temperature is $17^{\circ} \mathrm{C}$ while the reference temperature is assumed to be $25^{\circ} \mathrm{C}$, the temperature effect on the solubility is further considered. According to the solubility correlation in McGinnis et al. [8], the solubility of oxygen and nitrogen at $17^{\circ} \mathrm{C}$ water are greater than those at $25^{\circ} \mathrm{C}$ by $16.9 \%$ and $14.2 \%$ respectively, which tells the total volume of dissolved gas to be 5.86 liters, which is very close to our measurement result.

The simple average oxygen concentration of the extract gas is found to be $30 \%$ and the maximum of $31.9 \%$ is identified in the present experimental study.

\section{Conclusions}

The characterization of extracted dissolved gas from water is pursued by using a new and cost-effective degassing process based on vapor bubble diffusion. The proposed micro-vaporbubble based process has the advantage in that the concentration gradient or difference between water and bubbles can be maximized which accelerates the diffusion and extends the level of 
extraction. According to the present study results, the dissolved gas in water is successfully extracted and the limiting extractable volume is also identified that is very close to the solubility data. By using the proposed process higher, close to $100 \%$ of dissolved gas extraction is accomplished. The measured oxygen concentration of the gas extracted is found to be $30 \%$ in average, which is about $50 \%$ higher than the atmospheric air.

Through the present study, the availability of high oxygen content gas or air from water is clearly demonstrated experimentally, which may find many and diversified applications such as in life science and engineering, food processing, leisure industry, safety engineering, to mention a few. Further study may include but not limited to the uncertainty analysis for this process along with DO measurements, cost analysis, sensitivity analysis and parameter studies for best performance, device optimization or selection for micro-bubble-generators.

\section{Acknowledgements}

Authors appreciate the support from Mr. Jin-Goo Kim whose life- long experience and insight paved a safe and concrete way of achieving the finest experimental data.

\section{References}

[1] J. Lee, P. Heo, and T. Kim, "Theoretical model and experimental validation for underwater oxygen extraction for realizing artificial gills," Sensors and Actuators A: Physical, vol.284, pp.103-111, (2018)

[2] G. R. Greenbank and P. A. Wright, "The deaeration of raw whole milk before heat treatment as a factor in retarding the development of the tallowy flavor in its dried product," Journal of Dairy Science, vol.34, no.8, pp.815-818, (1951)

[3] Aeration and gas stripping - TU Delft OpenCourseWare, https://ocw.tudelft.nl/wp-content/uploads/Aerationand-gas-stripping-1.pdf

[4] D. Arthur, "How does deaerator work?" https://watertreatmentbasics.com/how-does-deaerator-work/, posted September 22, (2019)

[5] Y. D. Jun, J. S. Lee, S. W. Kim, and J. G. Kim, "Dissolved gas discharging apparatus and dissolved gas discharging method using the same," Korean Patent 10-2020-0002833(pending), (2020)

[6] Lide and R. David, "CRC handbook of chemistry and physics (85 $5^{\text {th }}$ ed.)," CRC Press, pp.6-8. ISBN 978-08493-0485-9, (2004)

[7] Y. D. Jun and J. S. Lee, "A new safe approach of evaluating the oxygen transfer efficiency (OTE) of underwater bubble diffusion," Journal of Green Engineering, vol.10, no.7, pp.4154-4165, (2020)

[8] D. F. McGinnis and J. C. Little, "Predicting diffused-bubble oxygen transfer rate using the discrete-bubble model," Water Research, vol.36, pp.4627-4635, (2002) 
This page is empty by intention. 